\title{
ANALYSIS OF THE ENGINE STRUCTURAL AND THERMAL STRESS
}

\author{
STAN Liviu-Constantin \\ Constanta Maritime University, Faculty of Naval Electro-Mechanics, Constanta, Romania \\ liviustan14@yahoo.com
}

\begin{abstract}
The paper aims to analyse the demands of four-stroke naval pistons. To begin with, a brief analysis of the evolution of shipbuilding was made. Mechanical requests are produced by the gas pressure force and inertial force of the alternate moving masses. Under its action the piston suffers an axial deformation. The thermal demands appearing in the engine are all the more important as the engine power is higher. The possibility of calculating them is more difficult due to the complexity of the thermogazodynamic phenomena in the engine cylinder. Thus, in the piston head, which comes in contact with both the hot gases and the fresh (much cooler) load, a non-stationary heat flow is installed which leads to a certain thermal regime of the engine. Considering the demands outlined in the last chapter, they lead to the final conclusion that although the most unfavourable loading situation was considered as the maximum pressure during the processes and even exaggerated in establishing the working conditions, the piston is still close to the elastic limit. This demonstrates that the way of calculating the dimensions of the piston is correct and safe, as long as its constructive dimensions are not oversized.
\end{abstract}

Key words: engine, structural, thermal, stress, piston, load.

\section{GENERIC PROBLEMS}

During the compression stroke, the air is pressed in the anteroom through the holes in the diffuser and ignites a small part of the injected fuel as the compressed air temperature in the ante chamber rises above the ignition temperature of the fuel. This partial firing produces an increase in the pressure in the ante chamber and sends the fuel unrelated to the cylinder through the holes in the diffuser at the beginning of the combustion stroke. Fuel mixes with hot air, producing burning and thus developing mechanical work. Increased pressure pushes the pistons downwards and rotates the knife shaft through the blades. The output power is transmitted further through the clutch mounted to the crankshaft flange.

The crankshaft is supported on 7 floor cams located in the engine crankcase. The rear bumper is the leading one. The bellows work 2 on a mane, and are fitted with a cuff on the head and a bronze bush on the leg.

Each cylinder has two exhaust valves and two intake valves, the stroke of which is made by a camshaft and by push-pulls, pushing spikes and spikes. For supercharged engines, the intake connections are connected by a collector with the starter blower stator (Figure 1).
Pumps required for engine operation as a feed pump, lubrication and cooling pump are mounted on the motor and driven by gears from the crankshaft. On the right side of the engine is the injection pump with the speed controller.

The fuel pump is mounted on the injection pump which is driven by a cam of the camshaft of the injection pump. The pump is also provided with a hand pump for priming when the engine is off.

The oil pump is mounted on the bearing cap no. 1 and works submerged in the oil bath. The water pump is mounted on the rear right of the engine crankcase. A pump for cooling water through the auxiliary water can be mounted in front of the engine and is supported by a trapezoidal belt from a wheel fixed to the crankshaft end.

The oil bath is cast from aluminium, with the recess in the back, which serves as a reservoir for the oil circuit. Inside the oil bath is provided with 4 stiffening transverse walls having communication ports. There is an oil drain plug in the back. The oil pan has a cast frame and holes for fixing to the engine crankcase. 


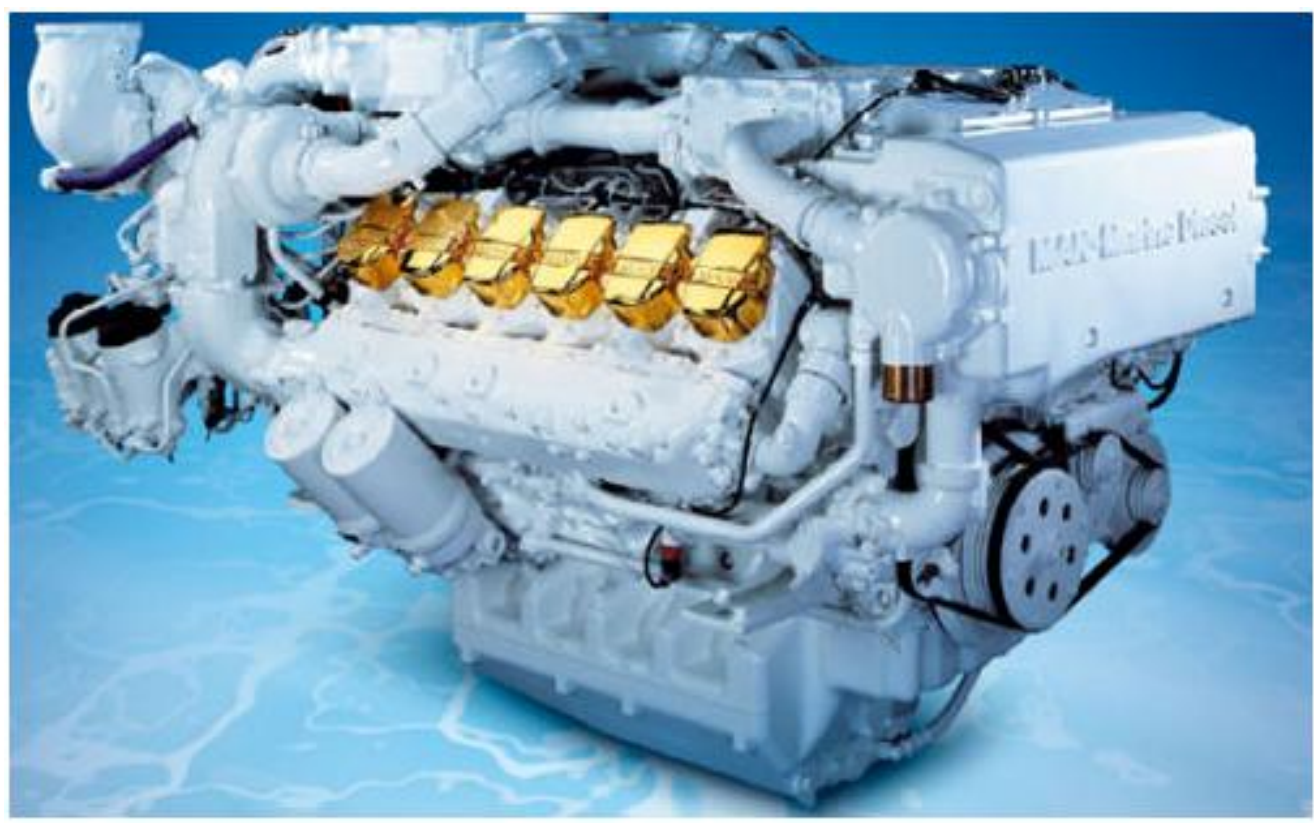

Figure 1 Engine type MAN 2842LE403

\section{THERMAL CALCULATION}

Thermal calculation of naval diesel engines aims at determining the state of the motor fluid state in its evolution during the operating cycle. With the help of these sizes, you can draw the indicated operating cycle diagram, which can be used to determine the main engine dimensions: the indicated and effective parameters, the main engine dimensions, the power and economy of the engine, and the forces acting on the engine parts.

According to the calculation method, analytical methods and graphical methods are based on thermodynamic diagrams.

By performing the thermal calculation, the state of the motor fluid state in its evolution within the operating cycle is determined. With the help of these sizes, you can draw the indicated operating cycle diagram, on the basis of which you can determine the main engine sizes: the indicated and effective parameters, the main construction dimensions, the engine power and economy, and the forces acting on the engine parts.

Engine data:

$$
\begin{aligned}
& \text { Pe }[\mathrm{kW}]=528 \mathrm{~kW} ; \\
& \mathrm{n}=1800 \text { [rot./min]; } \\
& \mathrm{i}=12 \mathrm{~V} ; \\
& \tau=4 ; \\
& \mathrm{D}=128 \mathrm{~mm} ;
\end{aligned}
$$

$$
\mathrm{S}=142 \mathrm{~mm}
$$

Since the increase in compressed air pressure and temperature increases its density, which leads to major calculation errors, the air is cooled in one or two chillers, depending on the compression level of the air and therefore the temperature of the air at the compressor outlet.

Between the two values obtained there is a percentage error that does not exceed the permissible limit of two percent:

$$
\Delta \mathrm{T}_{\mathrm{a}}=\frac{\left|\mathrm{T}_{\mathrm{a}}-\mathrm{T}_{\mathrm{a}}^{(\mathrm{gr})}\right|}{\mathrm{T}_{\mathrm{a}}} \cdot 100=0,72466457 \%
$$

Fluid pressure:

$$
\mathrm{Pa}=\xi \mathrm{a} \mathrm{ps}=2,464 \cdot 105 \mathrm{~Pa} .
$$

Fluid volume:

$$
\mathrm{V}_{\mathrm{a}}=\frac{\mathrm{m}_{\text {am"a" }} \mathrm{R}_{\text {am"a" }} \mathrm{T}_{\mathrm{a}}}{\mathrm{p}_{\mathrm{a}}}={ }_{11,71926861 \mathrm{~m}^{3}}
$$

Fill coefficient:

$$
\lambda_{\mathrm{v}}=\frac{\varepsilon \cdot \mathrm{p}_{\mathrm{a}} \cdot \mathrm{T}_{\mathrm{s}}}{(\varepsilon-1) \cdot\left(1+\gamma_{\mathrm{r}}\right) \mathrm{p}_{\mathrm{s}} \mathrm{T}_{\mathrm{a}}}=0,96
$$

The values obtained fall within the experimental limits indicated in the literature. Thus, for supercharged engines, $\mathrm{pa}=\left(\begin{array}{lllll}1,056 & \ldots & 3,85\end{array}\right) 10^{5} \mathrm{~Pa}$. Also, for supercharged engines, the temperature Ta has values 
between 300 and $400 \mathrm{~K}$ and the fill coefficient $\lambda \mathrm{v}$ between 0.85 and 1.10 .

To determine the average polytropic exponent of the compression process, the expressions of the average specific molar heat of the engine fluid are calculated initially. Using the expressions of the specific heat of the components and the composition of the motor fluid, it results:

We have values:

-pressure:

$$
\mathrm{p}_{\mathrm{c}}=\mathrm{p}_{\mathrm{a}} \varepsilon \mathrm{nc}=7,26268244 \cdot 106 \mathrm{~Pa}
$$

-volume:

$$
\mathrm{V}_{\mathrm{c}}=\mathrm{V}_{\mathrm{a}} / \varepsilon=0,976605 \mathrm{~m}^{3} ;
$$

-temperature:

$$
\mathrm{T}_{\mathrm{c}}=\mathrm{T}_{\mathrm{a}} \varepsilon^{\mathrm{n}_{\mathrm{c}}-1}=915,726^{\circ} \mathrm{K} .
$$

The usual values of these parameters in the case of supercharged engines are: $\mathrm{pc}=5 \ldots 10 \mathrm{MPa}$ and $\mathrm{T}_{\mathrm{c}}$ respectively $=700 \ldots 950{ }^{\circ} \mathrm{K}$. Therefore, the results obtained fall within the specified limits.

Based on the simplified hypothesis that internal energy varies linearly by temperature, this variation is plotted. Corresponding to this graph the temperature Ty $=1291{ }^{\circ} \mathrm{K}$ is obtained. The exact value of this temperature is:

$$
\mathrm{T}_{\mathrm{y}}=\mathrm{T}_{1}^{\prime}+\left(\mathrm{T}_{2}^{\prime}-\mathrm{T}_{1}^{\prime}\right) \cdot \frac{\left(\mathrm{U}_{\mathrm{am} " \mathrm{y}^{\prime \prime}}-\mathrm{U}_{\mathrm{am} 1}\right)}{\left(\mathrm{U}_{\mathrm{am} 2}-\mathrm{U}_{\mathrm{am} 1}\right)}=1479,17^{\circ} \mathrm{K} ;
$$

$$
\mathrm{V}_{\mathrm{y}}=\mathrm{V}_{\mathrm{c}}=0,9766 \mathrm{~m}^{3} \text {. }
$$

$$
\mathrm{p}_{\mathrm{y}}=\frac{\mathrm{m}_{\mathrm{am} " \mathrm{y}} \cdot \mathrm{R}_{\mathrm{am} " \mathrm{y}^{\prime \prime}} \cdot \mathrm{T}_{\mathrm{y}}}{\mathrm{V}_{\mathrm{y}}}=11,8961 \cdot 106 \mathrm{~Pa}
$$

A pressure increase ratio is thus achieved:

$$
\lambda_{\mathrm{p}}=\frac{\mathrm{p}_{\mathrm{y}}}{\mathrm{p}_{\mathrm{c}}}=1,63 .
$$

The values obtained correspond to the experimental limits between the parameters of the motor fluid in the state "y". Thus the temperature varies between 1000 and $1500 \mathrm{~K}$ and the pressure varies between py $=8 \ldots 14 \mathrm{MPa}$ for overcharged engines.

Based on the simplified hypothesis that internal energy varies linearly by temperature, this variation is plotted. Corresponding to this graph, the temperature is $\mathrm{Tz}=2021 \mathrm{~K}$. The exact value of this temperature is:

$$
\mathrm{T}_{\mathrm{z}}=\mathrm{T}_{1}^{\prime \prime}+\left(\mathrm{T}_{2}^{\prime \prime}-\mathrm{T}_{1}^{\prime \prime}\right) \cdot \frac{\left(\mathrm{I}_{\mathrm{am} \mathrm{z}^{\prime \prime}}-\mathrm{I}_{\mathrm{am} 1}\right)}{\left(\mathrm{I}_{\mathrm{am} 2}-\mathrm{I}_{\mathrm{am} 1}\right)}=2011,36363{ }^{\circ} \mathrm{K} \text {. }
$$

Fluid pressure :

$$
\begin{aligned}
& \mathrm{p}_{\mathrm{z}}=\mathrm{p}_{\mathrm{y}}=11,8961 \cdot 106 \mathrm{~Pa} ; \\
& \text { Volume : } \quad \mathrm{V}_{\mathrm{z}}=\frac{\mathrm{m}_{\mathrm{am} " \mathrm{z} "} \cdot \mathrm{R}_{\mathrm{am} " \mathrm{z}} \cdot \mathrm{T}_{\mathrm{z}}}{\mathrm{p}_{\mathrm{z}}}=1,3567 \mathrm{~m}^{3 ;}(15) \\
& \rho=\frac{\mathrm{V}_{\mathrm{z}}}{\mathrm{V}_{\mathrm{y}}}=1,3892 .
\end{aligned}
$$

Based on previous calculations, the operating cycle diagram shown in Figure 2.

Fluid pressure in the end of burning: 


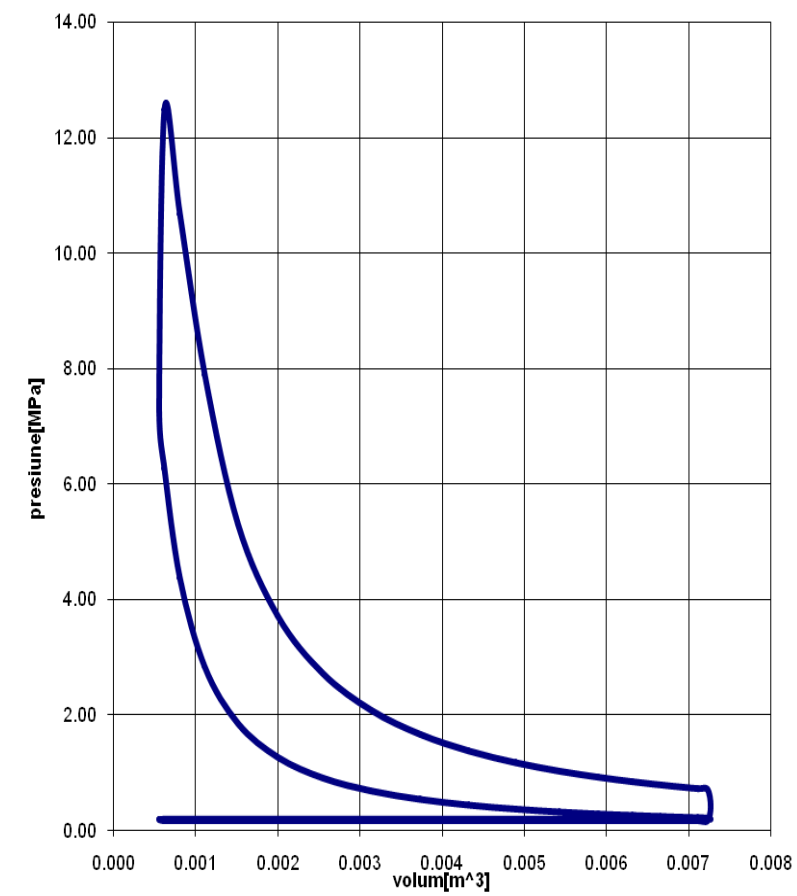

Figure 2 Indicate diagram

$$
\begin{gathered}
L_{i}=p_{z}\left(V_{z}^{\prime}-V_{y}^{\prime}\right)+\frac{p_{z} V_{z}^{\prime}-p_{b}-V_{b}^{\prime}}{n_{d}-1}+\frac{p_{a} V_{a}^{\prime}-p_{c} V_{c}^{\prime}}{n_{c}-1}= \\
=3,6560 \cdot 103 \mathrm{~J} ;
\end{gathered}
$$

-bore:

$$
\mathrm{D}=10^{3} \cdot \sqrt[3]{\frac{4\left(\mathrm{~V}_{\mathrm{a}}^{\prime}-\mathrm{V}_{\mathrm{c}}^{\prime}\right)}{\pi \cdot \psi_{\mathrm{d}}}}=128,36 \mathrm{~mm}
$$

-stroke:

$$
\begin{gathered}
\mathrm{S}=\psi \mathrm{d} \cdot \mathrm{D}=142,532 \mathrm{~mm} ; \\
\mathrm{R}=\mathrm{S} / 2=64,266 \mathrm{~mm} . \\
\mathrm{V}_{\mathrm{s}}=\frac{10^{-6} \pi \mathrm{D}^{2} \mathrm{~S}}{4}=2,0748 \mathrm{dm}^{3}
\end{gathered}
$$

\section{ANALYSIS OF THE ENGINE}

\section{STRUCTURAL AND THERMAL STRESS}

3.1. Steps to solve a problem using the finite element method

Step 1. Partition the analysis domain into finite elements. At this stage, the analyst chooses the type or types of fine elements appropriate to the problem solved, then divides the structure into finite elements. This
$\mathrm{V}_{\mathrm{t}}=\mathrm{i} \cdot \mathrm{V}^{\mathrm{s}}=24,8977 \mathrm{dm}^{3}$

Error:

$$
\Delta \mathrm{D}=\frac{\left|\mathrm{D}^{\text {(imp.) }}-\mathrm{D}^{\text {(calc) }}\right|}{\mathrm{D}^{\text {(imp.) }}}=0,33 \% .
$$

Effective power:

$$
\mathrm{P}_{\mathrm{e}}=\frac{\eta_{\mathrm{m}} \cdot \varphi_{\mathrm{r}} \cdot \mathrm{L}_{\mathrm{i}} \cdot \mathrm{n} \cdot \mathrm{i}}{30000 \cdot \tau}=529,77 \mathrm{~kW}
$$

operation, which is also called meshing, can be done using the computer. The finite element type is defined by several features, such as the number of dimensions (uni-, bi-, three-dimensional), the number of element nodes, associated approximation functions, and so on. Choosing the type of finite element is of great importance for the internal memory needs, the computing effort imposed on the computer and the quality of the results. 
The starting point for the mathematical construction of the different finite element methods is the observance of the following principles:

- using an approximation based on the use of simpler elements, for which we have a solution;

- Increasing the accuracy of the calculation by refining the discretization.

Step 2. Formation of the equations of the finite elements (elemental equations). The behavior of the material or environment within a finite element is described by the equations of the fine elements called elemental equations. They make up a system of equations of the element.

Elementary equations can be derived directly, by variational method, by the residual or residue method (Galerkin) or by the energy balance method.

Step 3. Assembling elementary equations in the system equations of the structure. The behavior of the entire structure is modeled by assembling the equation systems of fine elements into the system equations of the structure, which physically means that the equilibrium of the structure is conditioned by the equilibrium of the finite elements. By assembling it is necessary that in common nodes the elements or functions unknown have the same value.

Step 4. Implementing boundary conditions and solving the system equations of the structure. The system of equations obtained from the implementation of the boundary conditions corresponding to the concrete problem is solved by one of the usual processes, for example by eliminating Gauss or by decomposing Choleski, obtaining the values of the functions in the nodes. These are also called primary or first order unknowns.

Step 5. Making additional calculations to determine secondary unknowns. In some problems, after learning the unknowns, the analysis ends. This is usually the case for thermal conduction problems, where the primary unknowns are nodal temperatures. In other matters, knowing only the unknowns is not sufficient, the analysis must continue with the determination of the second or second order unknowns. These are derived from the superior order of the primary unknowns. Thus, for example, in mechanical elasticity issues, the primary unknowns are nodal displacements. With their help at this stage, we determine the secondary unknowns that are the specific deformations and tensions. In the case of thermal problems, the analysis can continue with the determination of the secondary unknowns, which are the thermal flux intensities (thermal gradients)

\subsection{Stages of finite element analysis}

With the Ansys software, simulation of operation under the conditions of gas discharge will be made to facilitate calculation.

Enhancement with finite elements has to go through the following steps:

defining the structure, its geometrical and elastic characteristics, the applied loads and the bearing conditions;

- $\quad$ schematic how the structure takes over the applied loads: membrane, beam slab, etc.

- individualization of local deviations of the structure, such as: additional stiffening, cutting and consolidation of the area;

- $\quad$ the choice of finite element types, from the program library, for modeling the structure, taking into account the deformation modes or the stresses that arise in the elements;

- meshing the structure into finite elements, taking into account: the geometrical dimensions of the structure, the elastic characteristics of the material, the edge conditions, the loads and the displacements imposed on the materials;

- $\quad$ checking input data for compatibility and accuracy;

- $\quad$ running the calculation program;

- $\quad$ verification of the obtained results.

\subsection{Working and structural analysis}

In this paragraph we calculate the following:

- choose the model of study using ANSYS software (Figure 3, Figure 4, );

- discretization of study domain (Figure 5;

- the final results- pressure force (Figure 6), total deformation (Figure 7), elastic stain (Figure 8), heat flux (total and directional)(Figure 9, Figure 10) and temperature distribution (Figure 11). 
$\boldsymbol{\Lambda}$ simulare piston - Workbench

File View Tools Units Extensions Help

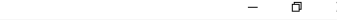

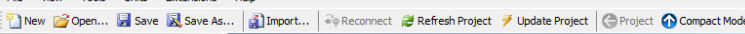

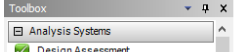

Analysis SYstems

Electric

Frolicit Dynamis

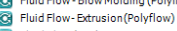

Fid Flid Flow (CFX)

Fid Fluid Flow (Fluent)

Harmonic Resporse

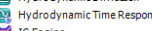

V. IC Engine
Linear Euckling
(iiii) Mannetostatic

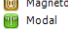

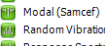

(iiii Responses Spectron

圈, Rigid Dynamic

Static Structural (Samcef)

Thermal-Electric

悬 Throughiflow

Tien Transient Thermal

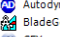

$8 \quad$ View All / Customize.
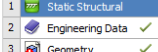

3 는

5 Mode

+ Model

6 Results

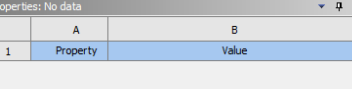

(2)

Figure 3 ANSYS windows

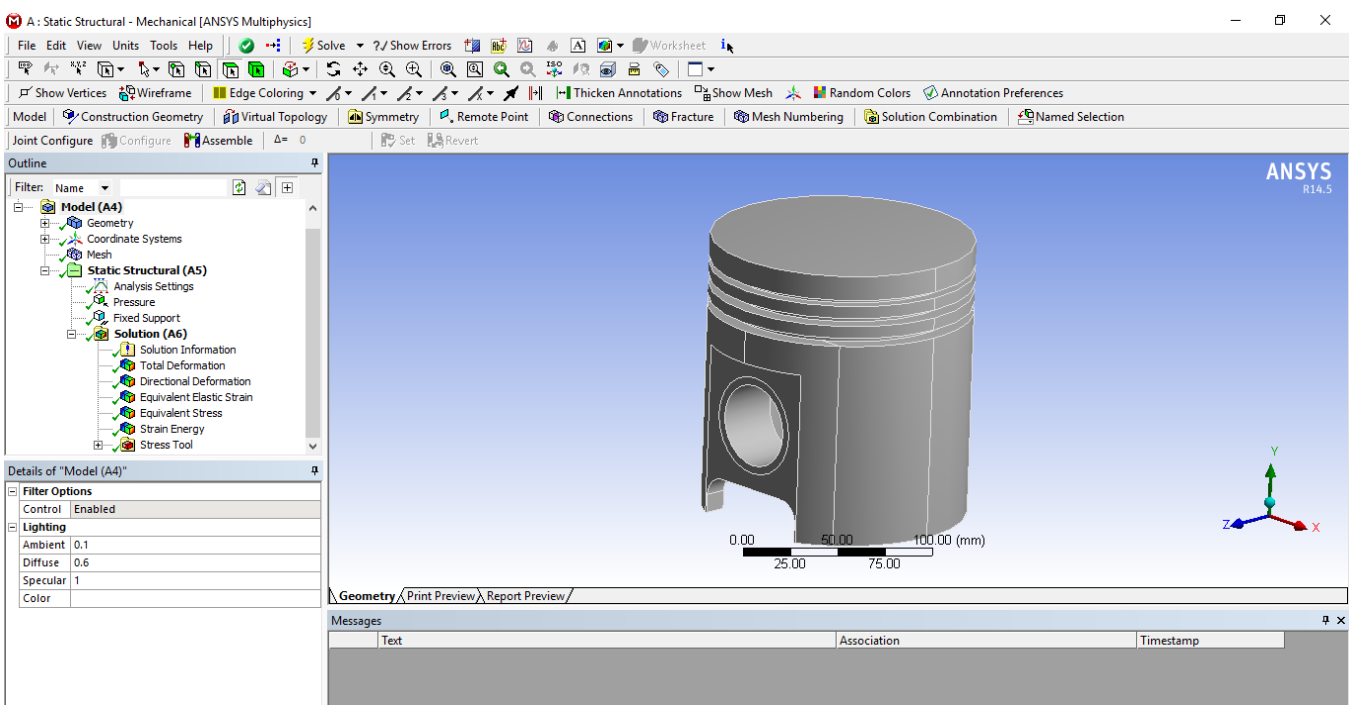

Figure 4 Model for study using ANSYS software 


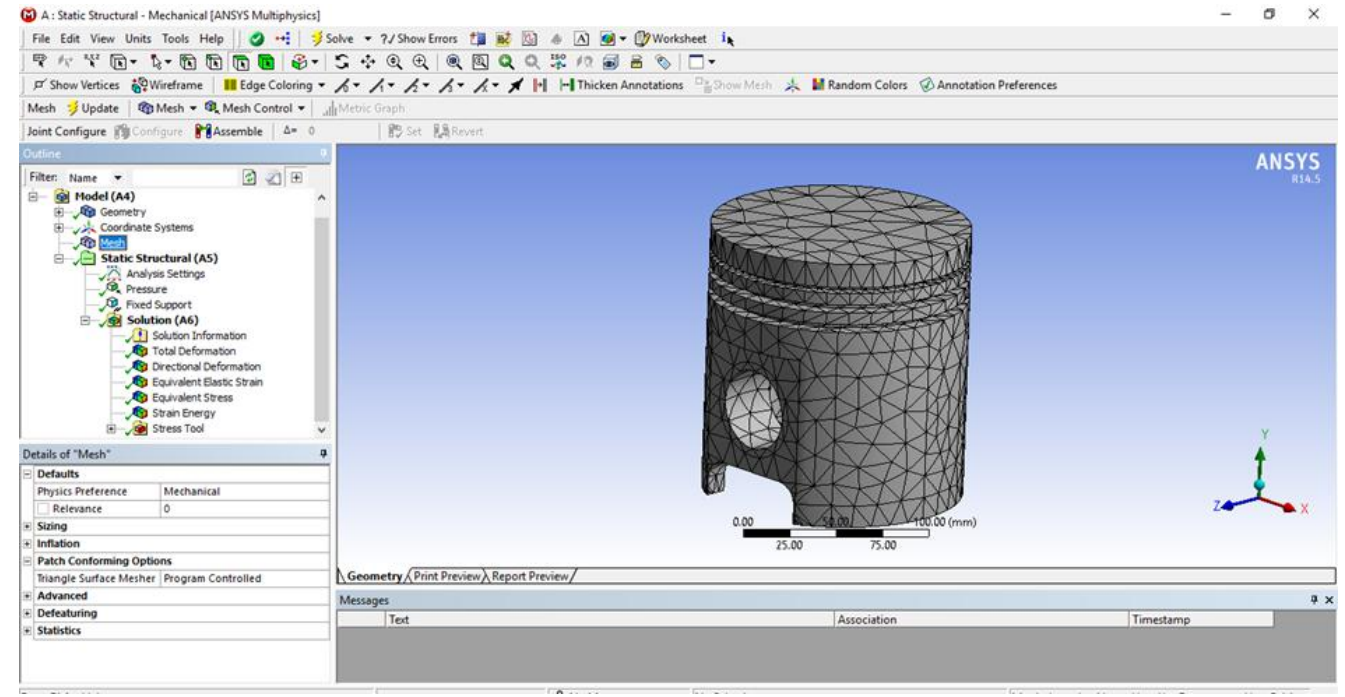

Figure 5 Meshing geometry

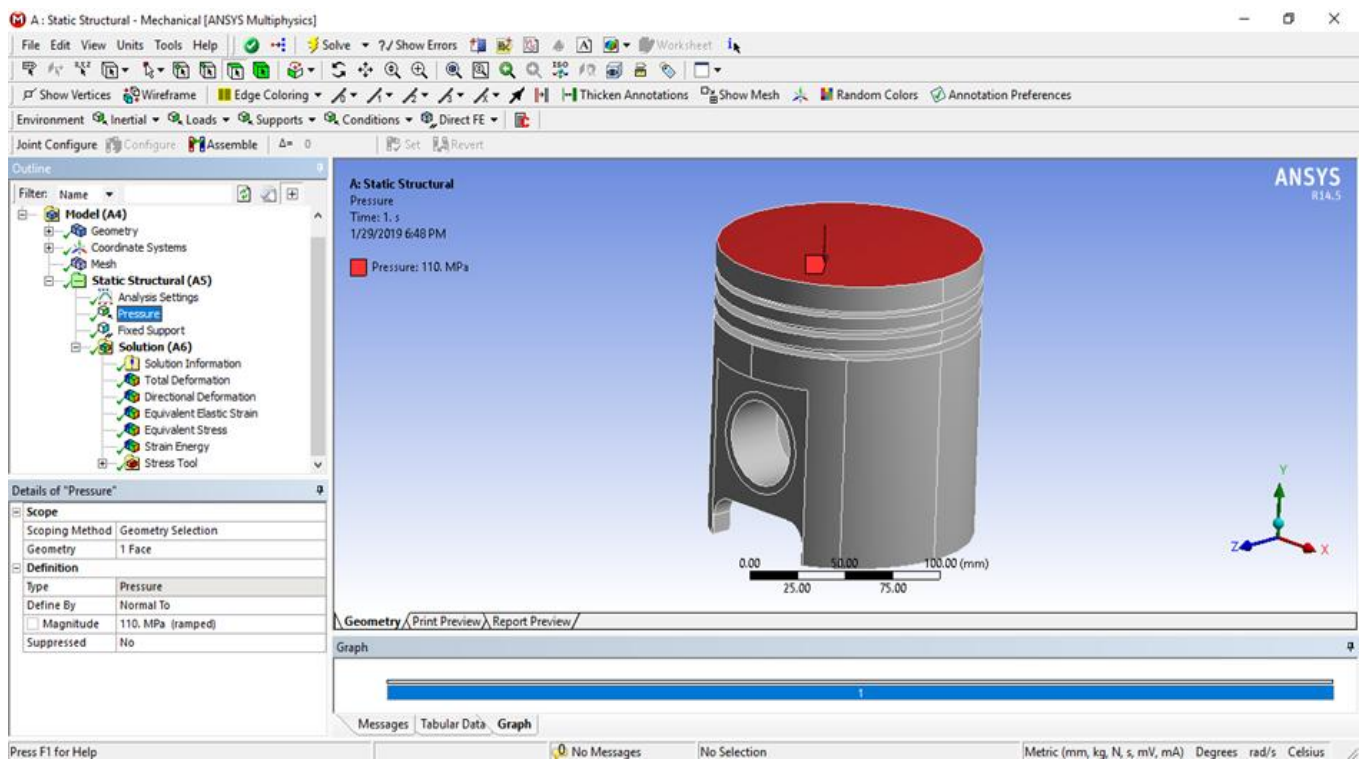

Figure 6 Pressure force 


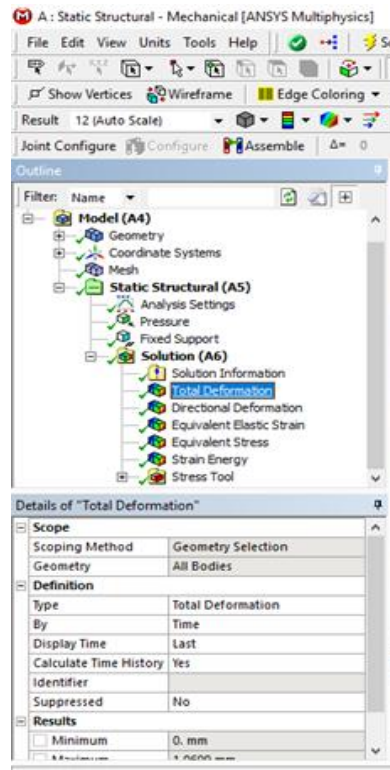

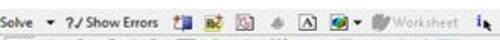

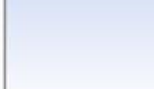

Messages Tabular Data Graph
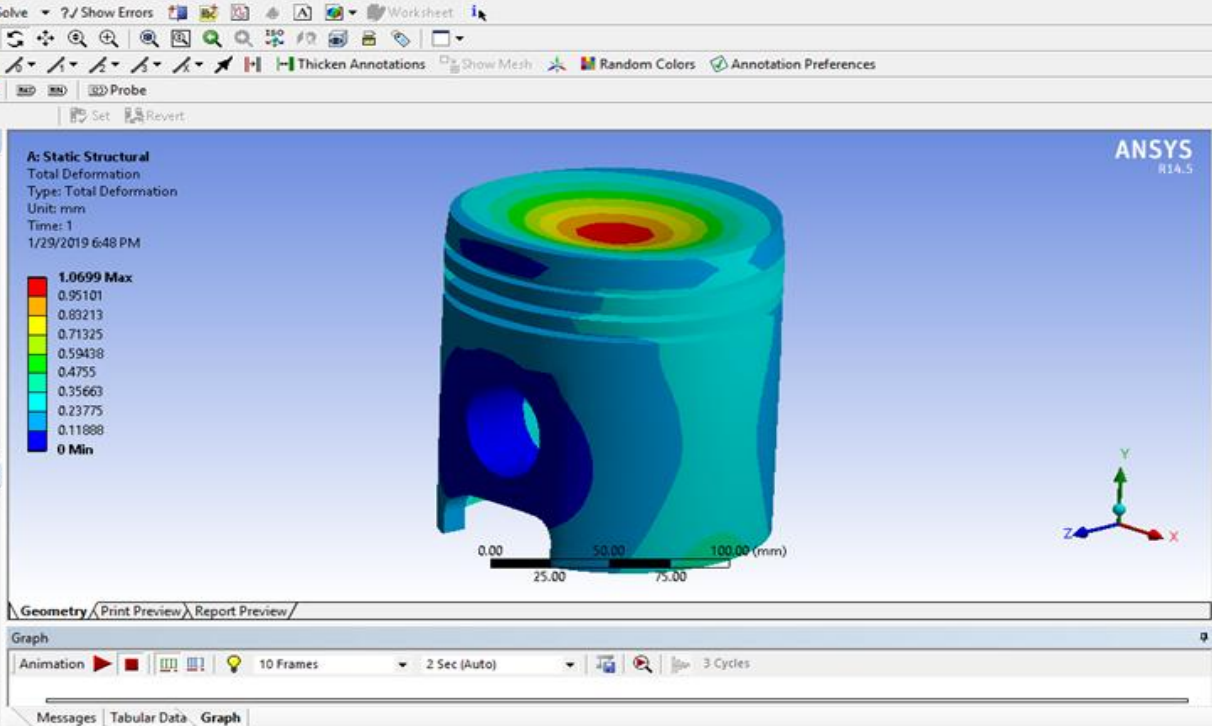

Figure 7 Total deformation

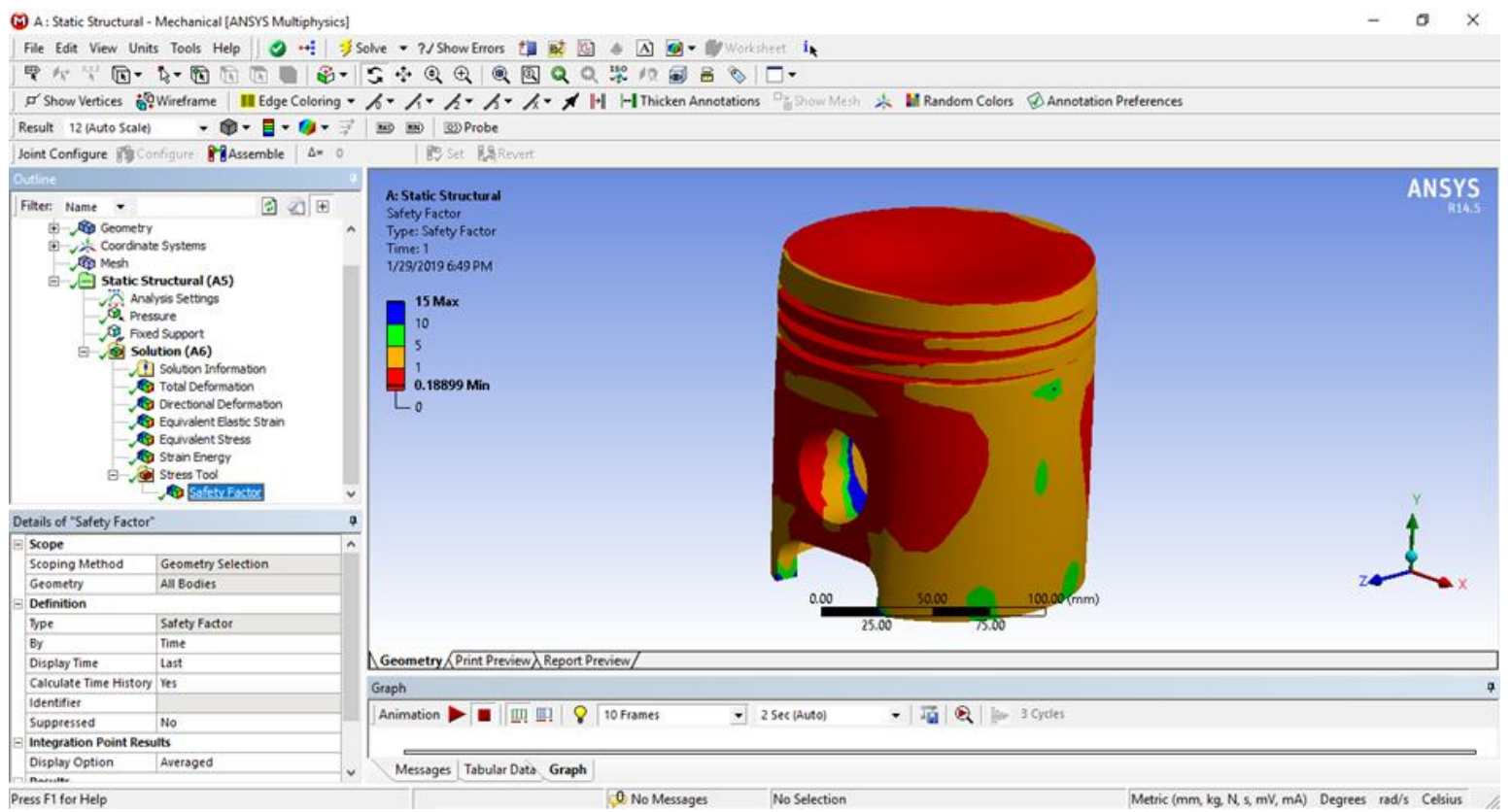

Figure 8 Elastic stain 


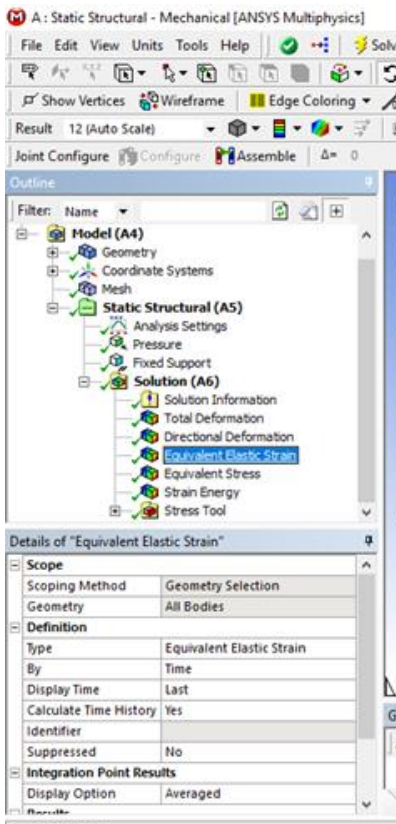

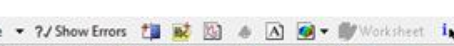

$\Delta G$ cometry/Print Previeun Recport Preview

Groph

Messages Tobular Doto Groph

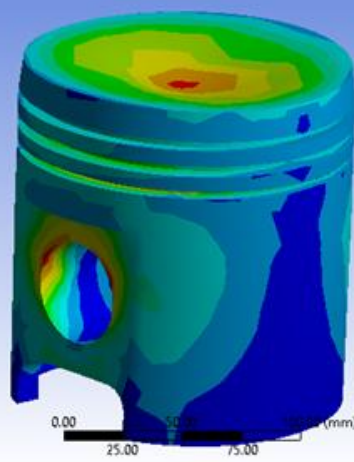

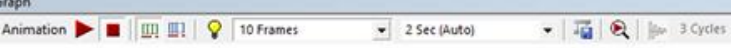

Figure 9 Total heat flux

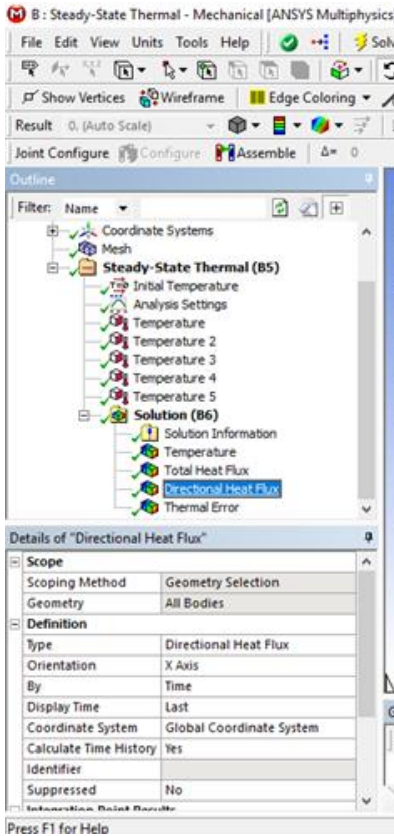

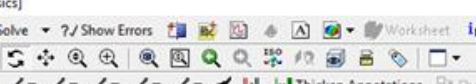

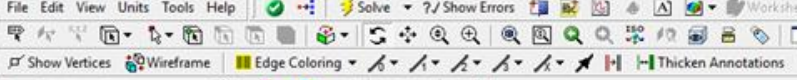

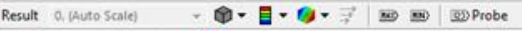

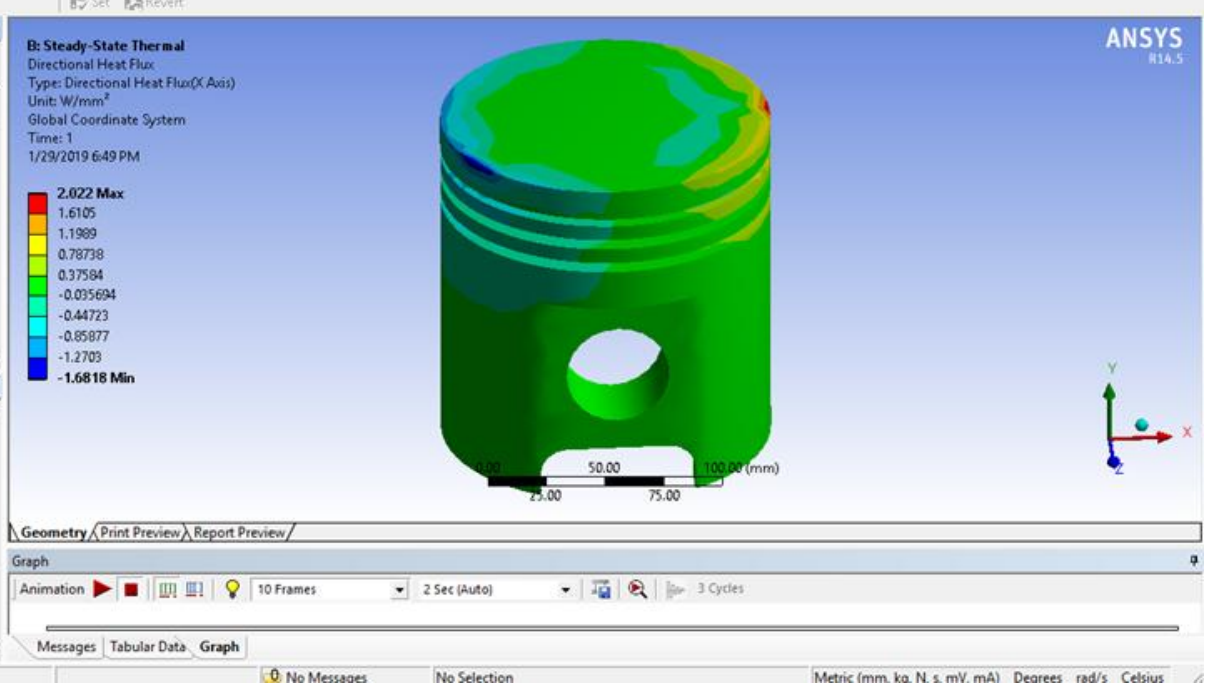

Figure 10 Directional heat flux 


\section{Journal of Marine Technology and Environment Year 2021, Vol.II}

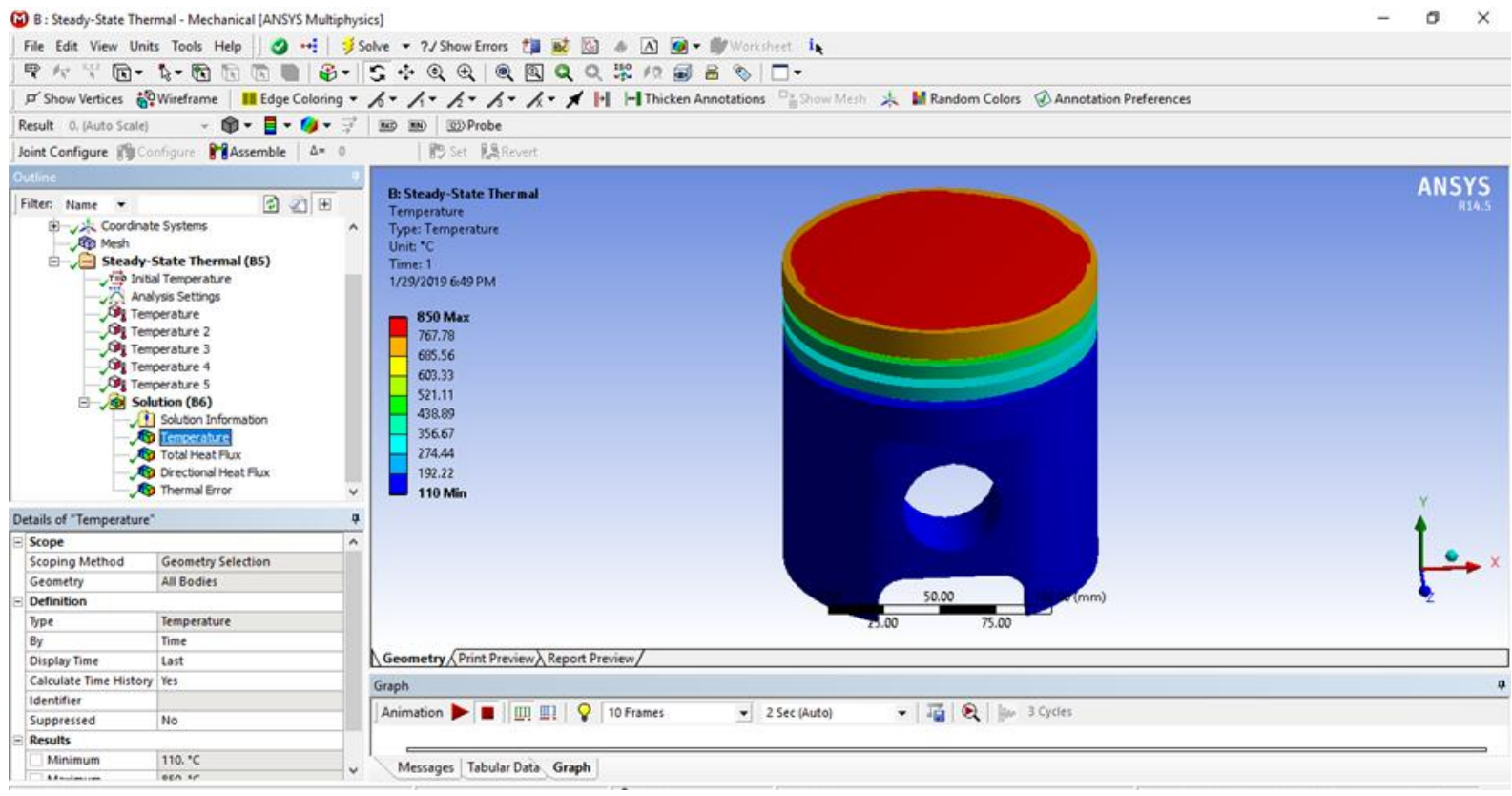

Figure 11 Temperature distribution

\section{CONCLUSIONS}

Following the analysis of the diagrams above, the following can be concluded:

The maximum displacement is $3.9219 \cdot 10-5 \mathrm{~m}$;

The maximum pressure is $7.8249 \cdot 107 \mathrm{~Pa}$;

The maximum value of the efforts is 0.00039125 $\mathrm{m} / \mathrm{m}$;

The safety factor is 3.1949 .

All of the above lead to the final conclusion that, although it was considered the most unfavorable loading situation, it was even exaggerated in establishing the forces and moments, the shaft is still close to the elastic limit. This proves that the calculation method of the piston is correct, and safe, provided that their dimensions are not oversized.

\section{REFERENCES}

[1]. Buzbuchi N, Stan L.C., 2008, "Procese si caracteristici ale motoarelor navale", 211 pp, Nautica
Publishing House, Naval Machines Collection, ISBN 978-973-7872-78-4, Constanta

[2]. Stan L.C., Călimănescu I., 2016, "Computer fluid dynamics (CFD) study of a micro annular gear pump", Atom-N Conference, Constanta

[3]. Stan L.C., 2015, "Seas and oceans, suppliers of the new and innovative renewable energy", Constanța Maritime University Annals, Volume 24, Constanța [4]. Buzbuchi N, Stan L.C., 2008, 'Constructia motoarelor navale si a sistemelor auxiliare ale acestora", pp 345, Nautica Publishing House, Naval Machines Collection, ISBN 978-973-7872-79-1, Constanta

[5]. Stan L.C., 2010, Naval machines, pp 348, Nautica Publishing House, Naval Machines Collection, ISBN 978-606-8105-17-8, Constanta

[6]. Man B\&W Diesel A/S - „MAN B\&W Lubricator System for Cutting the Cylinder Oil Bill and Reducing Emissions on MAN B\&W Two-Stroke Marine Engines, https://man-

es.com/applications/projectguides/2stroke/content/epub/ S50ME-B9_3.pdf

[7]. www.marine.man.eu 